\title{
ADVANTAGES OF STEEL FIBRE REINFORCED CONCRETE IN INDUSTRIAL FLOORS
}

\author{
Murugesan $\mathbf{M}^{\mathbf{1}}$, Dashrath Rajpurohit ${ }^{2}$ \\ ${ }^{1}$ Assistant General Manager, Civil \& Structural, Larsen \& Toubro Technology Services, Tamilnadu, India \\ ${ }^{2}$ Structural Engineer, Civil \& Structural, Larsen \& Toubro Technology Services, Tamilnadu, India
}

\begin{abstract}
Ground floor slabs are integral to the efficient operation of an industrial facility. A well designed and constructed floor will increase productivity, reduce maintenance of the building and increase the life of the equipment using the floor. Industrial floor slab has common requirements of high strength, toughness, crack control and durability among others. Most of the industrial floors are constructed using the conventional grade slab where reliance is only on the strength of concrete, and reinforcement is used only for crack control and shrinkage. The use of steel fibres in concrete is advantageous over conventional grade slab wherein the residual load carrying capacity of fibres is used and thus, increases the strength and toughness and gives economy in floor thickness apart from saving in construction time. This paper gives an insight into the advantages of steel fibre reinforced concrete in industrial floors. This work is based on structural design experience of the authors in steel fibre reinforced concrete floor slab for industrial projects and in particular the project recently completed for a food and beverage industry.
\end{abstract}

Keywords: aspect ratio, industrial floors, slabs-on-grade, steel fibres, steel fibre reinforced concrete (SFRC)

\section{INTRODUCTION}

Industrial floors are normally subjected to various types of loading. There will be heavy rack posts, material handling equipment like forklifts, stacked loads, heavy tanks and other processing machines. These floors need to cater to stringent standards, especially in food and beverage industries, where hygiene and appearance are of great significance in addition to strength and toughness. The normal practice in industries is to provide a concrete grade slab with reinforcement in the upper one-third layer to cater to shrinkage and crack-control. These grade slabs have to be designed as per the elastic method, and hence thickness provided is same as that of an unreinforced slab. As reinforcement is located in a specific region, it does not serve the purpose of crack control throughout the slab. To use the plastic analysis approach and design thinner sections, we need to provide a reinforcing material that can provide the required ductility in the slab. For this purpose, reinforcement needs to be provided at the bottom of the slab, either in form of bars, fabric or steel fibres. The current paper deals only with the provision of fibres in achieving the ductility.

\section{AN OVERVIEW ABOUT THE PROJECT}

This new green field project for food and beverage industry is located near to Chennai. The project consists of three phases with total estimated built up area of $100,000 \mathrm{~m}^{2}$. Currently, phase- 1 with $25000 \mathrm{~m}^{2}$ is completed and plant is under operation. The major buildings include the main plant building $(245 \mathrm{~m} \times 60 \mathrm{~m})$ with pre-engineered building structure (PEB), utility building, admin building and other supporting facilities. The two ends of the main plant building are reserved for raw material and finished good warehouses and central portion caters to process and packaging line. SFRC was used for main plant building grade slab and external roads.

\section{APPLICATION OF STEEL FIBRE REINFORCED SLAB}

With advance in technology, warehouse areas now-a-days are fully utilized using automated systems and radio shuttles. A similar racking system was used in this plant with continuous storage. Racks were up to $11 \mathrm{~m}$ high $(\mathrm{G}+6$ Storage). Design point loads were as high as $93 \mathrm{kN}$ with base plate of $170 \mathrm{~mm} \times 180 \mathrm{~mm}$, and spacing between two legs was $1400 \mathrm{~mm}$. The critical loads were mostly point loads in the warehouse and tank storage areas. Tank area had design load of $110 \mathrm{kN}$ per leg with a base plate of 125 mm diameter.

The grade slab was first checked for a conventional design with slab designed using elastic analysis. Reinforcement was provided for controlling cracks and shrinkage. The thickness arrived was $300 \mathrm{~mm}$ at most places. The design was then checked for steel fibre reinforced concrete using plastic analysis and thickness arrived was $200 \mathrm{~mm}$ in most places and $220 \mathrm{~mm}$ in a strip in the process area that had large storage tanks.

One of the characteristics of steel fibre is its aspect ratio. It is the ratio of its length to diameter. The more the aspect ratio, the better will be the fibre performance provided the required workability and uniform distribution is achieved. This is because higher aspect ratio gives better pull-out resistance. However, very high aspect ratio can lead to problems of balling. To prevent this, we chose fibres of 
hooked ends. We used fibres of $0.75 \mathrm{~mm}$ thickness and 60 $\mathrm{mm}$ length, thus having an aspect ratio of 80 . For deciding slab thickness, the critical loads in all areas were the point loads. We used variable dosage and grades of concrete to achieve an economical solution as providing uniform design to complete area would have led to a very conservative design in most places.

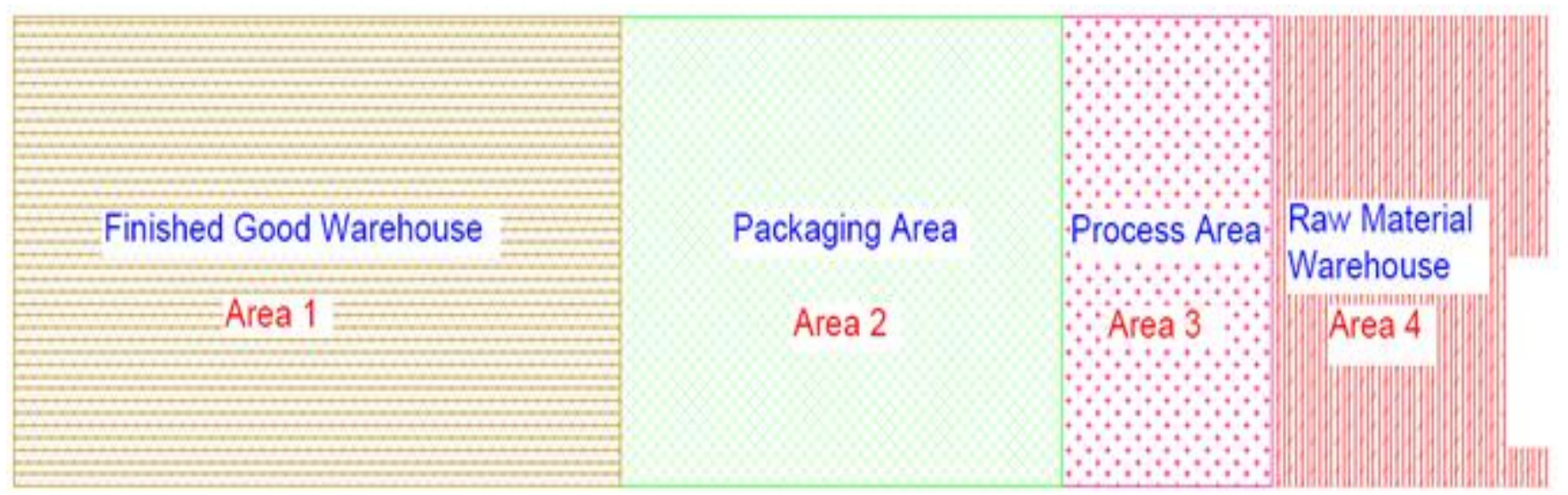

Fig 1 Main Plant Building layout (245 m x 60 m) with demarcation of different functional areas

The various concrete grade, slab thickness and fibre dosage used have been shown in Table 1 .

Table 1 Concrete Grade and thickness used for various

\begin{tabular}{|c|c|c|c|c|c|}
\hline \multicolumn{6}{|c|}{ areas } \\
\hline $\begin{array}{l}\text { Area } \\
\text { Label }\end{array}$ & $\begin{array}{l}\text { Maximu } \\
\text { m Point } \\
\text { Load } \\
(\mathbf{k N})\end{array}$ & $\begin{array}{l}\text { Base } \\
\text { plate } \\
\text { size }(\mathbf{m m} \\
x \mathbf{m m})\end{array}$ & $\begin{array}{l}\text { Grad } \\
\text { e of } \\
\text { Concr } \\
\text { ete }\end{array}$ & $\begin{array}{l}\text { Slab } \\
\text { Thickn } \\
\text { ess } \\
(\mathbf{m m})\end{array}$ & $\begin{array}{l}\text { Fibre } \\
\text { Dosa } \\
\text { ge } \\
(\mathbf{k g} / \\
\left.\text { m }^{3}\right)\end{array}$ \\
\hline $\begin{array}{l}\text { Area } \\
1\end{array}$ & 93 & $\begin{array}{ll}170 & \mathrm{x} \\
180 & \end{array}$ & M35 & 200 & 20 \\
\hline $\begin{array}{l}\text { Area } \\
2\end{array}$ & 30 & $\begin{array}{ll}150 & \mathrm{x} \\
150 & \end{array}$ & M25 & 150 & 18 \\
\hline $\begin{array}{l}\text { Area } \\
3\end{array}$ & 110 & 125 ( dia & M35 & 220 & 15 \\
\hline $\begin{array}{l}\text { Area } \\
4\end{array}$ & 81 & $\begin{array}{ll}100 & \mathrm{x} \\
180 & \end{array}$ & M35 & 200 & 18 \\
\hline
\end{tabular}

\section{HOW FIBRES WORK AND THEIR EFFECTS}

The behaviour of grade slab is different than that of a roof slab as it rests directly on the soil. This is why, if at all conventional reinforcement is added to grade slab, it is added only for crack control at the top layer, preferably in the top one-third layer of the slab. Reinforcement below the mid depth is uncalled for both behaviourally and economically. This leads to very limited crack control in conventional grade slabs, as the top reinforcement is localized and there is no mechanism for arresting cracks below the mid depth. Also, the moment resistance is provided completely by the concrete in the slab.

Steel fibres, are spread throughout the slab thickness, and hence can arrest the cracks at the location they originate. Also, the fibres provide a post-cracking moment resisting capacity, increased energy absorption and impact resistance. The extent to which these benefits are derived from SFRC depends on the type of fibre, and the fibre content (fibre percentage by volume and number of fibres). The length to diameter ratio mentioned earlier is an important governing factor. As the stress transfer from the concrete matrix to the fibres happens by interfacial shear, the greater the interfacial surface area, greater is the fibre efficiency. Hence fibres with greater aspect ratio have greater efficiency (i.e. more pull-out resistance). However, there is a limit to this, as very high aspect ratio will reduce the workability of the concrete mix. Most practical applications use an aspect ratio less than 100.

The stress in FRC is shared by the concrete matrix and fibre until the concrete cracks. After cracking, the total stress is gradually transferred to the fibres. The resistance to pull-out of fibre will depend, apart from the aspect ratio, on the shape of fibre. Non round fibres, fibres with hooked ends etc. provides more pull-out resistance compared to plain round fibres. However, fibre should be such that the failure should happen by pull-out only and the resistance to pull-out should not be so much as to cause breaking of fibre in tension. A pull-out type of failure gives gradual and ductile failure.

\section{DESIGN OF GRADE SLAB FLOOR}

The structural design of grade slabs involves estimating the ultimate moments and stresses that will act for a given configuration of loads and effects, followed by identifying the necessary resistance that must hold up to these acting stresses. The stresses depend on slab thickness, continuity, subgrade modulus/stiffness, construction method and quality, and magnitude and position of loads on the slab. The ground supported slab can be pictured as plate resting on a set of springs represented by the modulus of subgrade reaction.

There are various methods of arriving at the design thickness of grade slabs and appropriate reinforcements depending on the materials of construction chosen. The 
conventional methods for design of grade slabs are based on elastic analysis, and are widely used. Inelastic methods of design, using yield line analysis are used only for slabs which possess sufficient ductility, i.e. necessary reinforcement in terms of fibres or reinforcement bars to allow for redistribution of stresses.

It is essential to understand the loads on the slab that cause critical stress conditions. Generally, the ultimate stresses are governed by rack loads, wheel loads (from material handling equipment), with different load conditions such as edge load condition, corner load condition and interior load condition.

\subsection{Computation of Moment Capacity}

The inelastic moment capacity in the SFRC slab is taken as the post-cracking moment carrying capacity, which is a function of the equivalent flexural strength of SFRC. Consequently, the inelastic positive sagging moment capacity per unit length for a slab of thickness $h$ is estimated as,

$$
M_{p}=f_{e, 3 k}\left(\frac{h^{2}}{6}\right)
$$

where, $f_{e, 3 k}$ is the characteristic equivalent flexural strength of concrete (obtained from four point bending test of SFRC beam until a $3 \mathrm{~mm}$ deflection).

The negative moment capacity is the limit of onset of cracking on the top of the slab due to hogging. It is important to note that even after the onset of cracking on top; the SFRC slab will have residual moment capacity owing to the inherent ductility of the matrix. The negative capacity at Ultimate Limit State is a function of the flexural strength (or modulus of rupture) of the concrete (obtained from the same flexural test) given as:

$$
M_{n}=f_{c t k, f l}\left(\frac{h^{2}}{6}\right)
$$

where, $f_{c t k, f l}$ is the characteristic flexural strength of the concrete.

The corresponding moment estimates are used for SFRC in the inelastic design equations suited to different yield patterns depending on the load case. Using yield lineanalysis, for a true point load, the collapse load $P_{u}$ in the interior of a slab as per Meyerhof is given as,

$$
P_{u}=2 \pi\left(M_{p}+M_{n}\right)
$$

From equation (1) and (2),

$$
\begin{aligned}
& M_{p}+M_{n}=\left(f_{e, 3 k}+f_{c t k, f l}\right)\left(\frac{h^{2}}{6}\right) \\
& M_{p}+M_{n}=f_{c t k, f l}\left(\frac{h^{2}}{6}\right)\left(1+R_{e, 3}\right)
\end{aligned}
$$

The advantage provided by the fibres is quantified here by $\mathrm{R}_{\mathrm{e}, 3}$ which is defined as the ratio of equivalent flexural strength to the flexural strength up to a deflection of $3 \mathrm{~mm}$. Note that a partial safety factor for concrete is applied to the above equations to get the design moment capacity. Thus, $\mathrm{R}_{\mathrm{e}, 3}$ can be used to quantify the residual strength provided by fibre reinforced concrete. Flexural tests were done on specimens from site to obtain the $R_{e, 3}$ values.

\section{FLEXURAL AND TOUGHNESS TEST ON SPECIMENS}
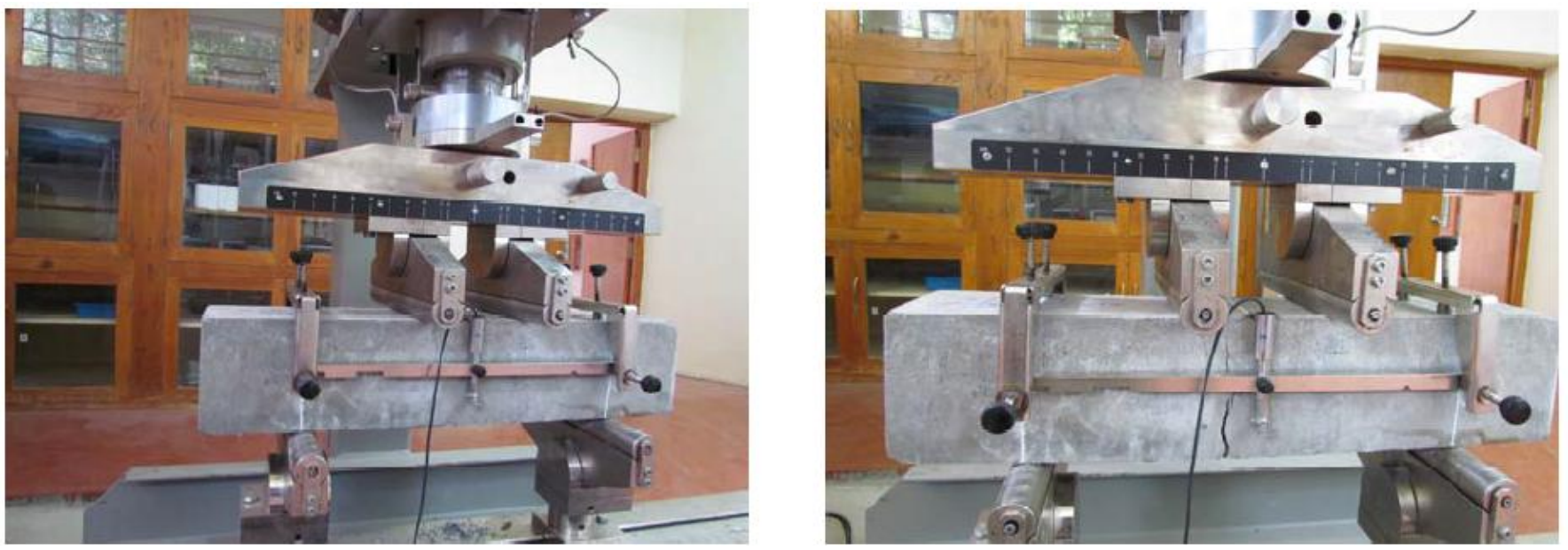

Fig. 2 Loading set-up and yoke fixed to the neutral axis of the prism

Flexural toughness tests were performed at IIT Madras on six specimens casted at site. The tests conform to ASTM C 1609-10 and JSCE SF-4. The specimens were of M25 grade of concrete with $18 \mathrm{~kg} / \mathrm{m}^{3}$ of fibre dosage. Glued fibres of length $60 \mathrm{~mm}$ and diameter $0.75 \mathrm{~mm}$ were used.
The specimens cast were $150 \mathrm{~mm}$ x $150 \mathrm{~mm}$ x $700 \mathrm{~mm}$, and were tested in a $1 \mathrm{MN}$ controls closed loop servo controlled testing system at the age of 28 days. The prism is tested as a simply supported beam with span of $450 \mathrm{~mm}$ and is loaded at third points. The test is performed by increasing the load 
at a constant rate of $100 \mathrm{~N} / \mathrm{s}$ up to a load corresponding to about $40 \%$ of the estimated peak load, and then by increasing the deflection at a constant rate of $1.0 \pm 0.1$ $\mathrm{mm} / \mathrm{min}$. The test is terminated after reaching a deflection of at least $3 \mathrm{~mm}$.

\section{RESULTS}

The load deflection curves obtained for the six specimens are shown below in Fig. 3.

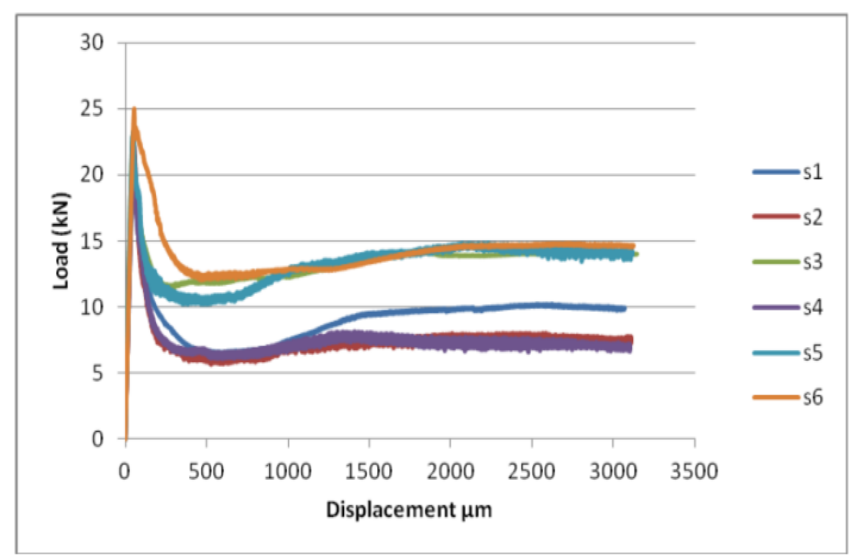

The toughness $\mathrm{T}$, which corresponds to the energy absorbed by the beam, is given by the area under the load displacement diagram up to a mid-point deflection of $\delta_{150}=$ $\operatorname{span} / 150=450 / 150=3 \mathrm{~mm}$.

The equivalent flexural strength at deflection of $3 \mathrm{~mm}$, is calculated as,

$$
f_{e 3, k}=\frac{T L}{\delta_{150} b h^{2}}
$$

Here, $\mathrm{L}$ is the test span $(450 \mathrm{~mm})$, and $\mathrm{b}$ and $\mathrm{h}$ are the width and depth of section respectively. The mean concrete flexural strength is calculated from the maximum load $\mathrm{P}$ indicated by testing machine before failure.

$$
f_{c t m, f l}=\frac{P L}{b h^{2}}
$$

The following table shows $R_{e, 3}$ value obtained from flexural strength and equivalent flexural strength

Fig 3 Load deflection curves of the Tested Samples

Table 2 Results of Flexural Toughness Test

\begin{tabular}{|l|l|l|l|l|l|}
\hline $\begin{array}{l}\text { Specimen } \\
\text { Notation }\end{array}$ & $\begin{array}{l}\text { Toughness } \\
\text { Area under the } \\
\text { graph }\end{array}$ & $\begin{array}{l}\text { Equivalent } \\
\text { Flexural } \\
\text { Strength fe3,k }\end{array}$ & $\begin{array}{l}\text { Peak } \\
\text { Load P }\end{array}$ & $\begin{array}{l}\text { Flexural } \\
\text { Strength }\end{array}$ & Average \\
\cline { 2 - 5 } & $\mathbf{N}-\mathbf{m m}$ & $\mathbf{N} / \mathbf{m m} \mathbf{2}$ & $\mathbf{k N}$ & $\mathbf{N} / \mathbf{m m}^{\mathbf{2}}$ & $\mathbf{\%}$ \\
\hline S1 & 28185 & 1.253 & 21.45 & 2.86 & $\mathbf{4 9 . 2 2}$ \\
\hline S2 & 23479 & 1.044 & 22.43 & 2.99 & \\
\hline S3 & 41998 & 1.867 & 23.03 & 3.07 & \\
\hline S4 & 23579 & 1.048 & 21.3 & 2.84 & \\
\hline S5 & 41990 & 1.866 & 23.25 & 3.1 & \\
\hline S6 & 44113 & 1.961 & 25.05 & 3.34 & \\
\hline
\end{tabular}

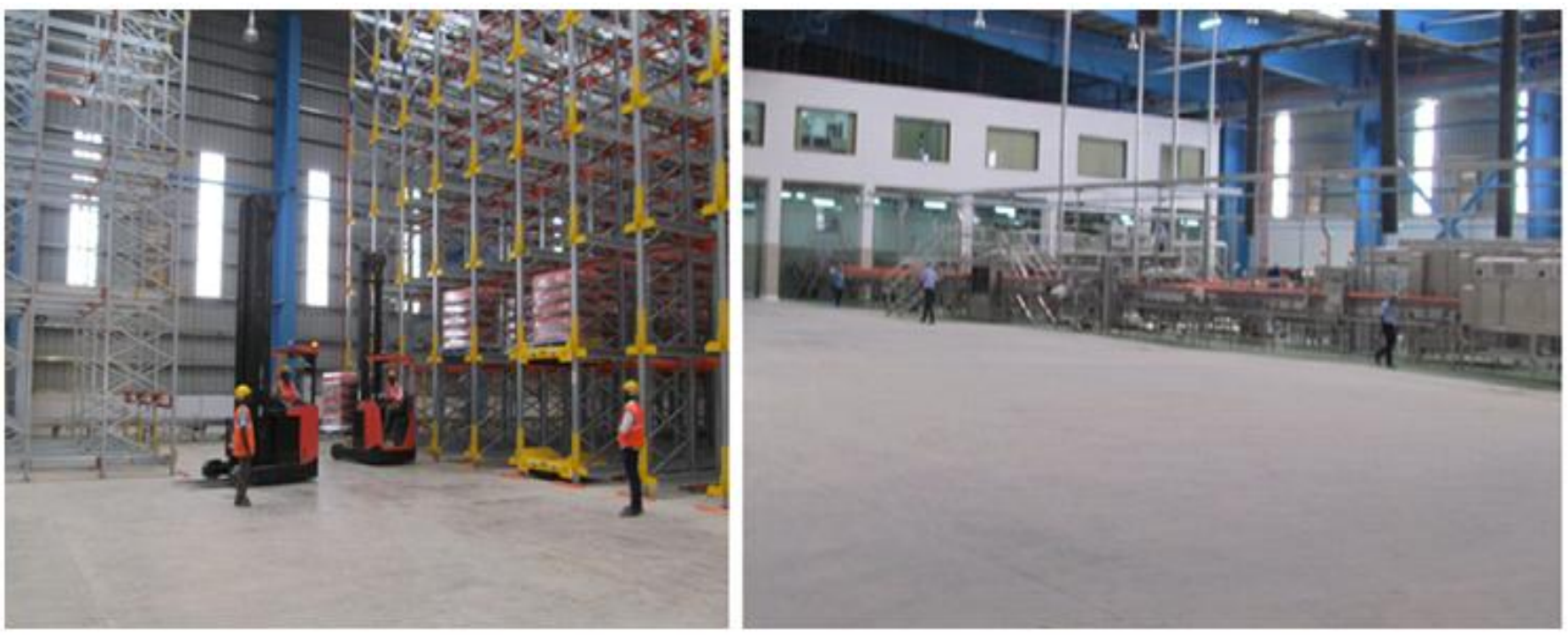

Fig 4 Steel fibre reinforced concrete slab at site after construction 


\section{CONCLUSION}

From the table 2, it can be seen that the $R_{e, 3}$ value obtained for a $18 \mathrm{~kg}$ dosage is $49.22 \%$ or about 0.5 . It shows that the moment resistance capacity for this concrete slab post first crack is roughly $50 \%$ more than that of plain concrete. For M 35 concrete with $20 \mathrm{~kg}$ dosage of the same fibre had shown $\mathrm{R}_{\mathrm{e}, 3}$ values of up to $71.6 \%$ on an average.

Thus, we were able to achieve significant toughness and moment resistance capacity for the fibre reinforced slab with thinner sections, thereby providing a durable and economical solution for the floor. Calculations were done to compute the cost benefit achieved compared to conventional slab, and an approximate saving of $10 \%$ of the grade slab cost was achieved. The above advantages show that steel fibre reinforced concrete can be beneficial for applications in industries having high loads and loading pattern similar to this project.

\section{ACKNOWLEDGEMENTS}

The authors thank Mr. M Duraisami, Senior Deputy General Manager (Head, Civil \& Structural), L\&T Technology Services for his support and guidance throughout the project. The authors express their gratitude to Dr. Ravindra Gettu, Professor, Department of Civil Engineering, IIT Madras for the help in testing the samples at IIT Madras. The authors also thank Mr. Navneet Narayan, Technical Manager, Bekaert Industries Pvt Ltd and Mr. Ramakrishnan S, Regional Manager, Bekaert Industries Pvt Ltd for supplying the fibers and providing all necessary technical assistance.

\section{REFERENCES}

[1] RILEM TC 162-TDF: "Test and design methods for steel fibre reinforced concrete," RILEM TC 162TDF, vol. 36, pp. 560-567, October 2003.

[2] Guidance for the Design of Steel-Fibre-Reinforced Concrete, Technical Report No. 63, Cement and Concrete Association

[3] Concrete Industrial Ground Floors, Technical Report No. 34, Cement and Concrete Association

[4] Guide to Design of Slabs-on-Ground, ACI-360R-10

[5] Design considerations for Steel fiber Reinforced Concrete, ACI 544.4R-88

[6] Fiber Reinforce Concrete, ACI 544.1R-24

[7] Concrete Floor and Slab construction, ACI 302.1R35

[8] Standard Test Method for Flexural performance of Fiber-Reinforced Concrete, ASTM C-1609-12

[9] Slab thickness Design for Industrial Concrete Floors on Grade, Portland Cement Association, Robert G. Packard, 1996

[10] Guidance for the design of plain jointed rigid pavement for Highways, IRC:58:2002, Indian Roads Congress 2002

[11] Guidelines for Design and Construction of Fibre reinforced Concrete Pavements, IRC:SP:46-2013, Indian Roads Congress, 2013

\section{BIOGRAPHIES}

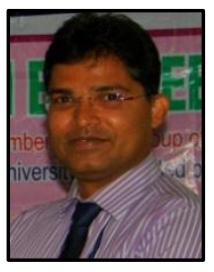

Murugesan M received Master's degree in Structural Engineering from Anna University, India in 2005. He joined as a Structural Engineer in Larsen \& Toubro Ltd in 2005 and currently working as an Assistant General Manager. He is having professional experience in civil and structural design, structural consultancy, project management for industrial, high-rise structures, commercial, residential, hospitals and institutional projects in India, USA, Middle East and East Africa.

$\mathrm{He}$ is a technical committee member in Indian Concrete Institute (ICI) committee constituted to prepare standard for industrial concrete flooring. $\mathrm{He}$ is certified Chartered Engineer and Member of Institution of Engineers (India). He is fellow member of Institutions of Valuers (India) and Certified Project Manager by L\&T Institute of Project Management.

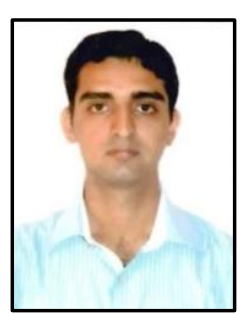

Dashrath Rajpurohit received his Bachelor of Technology degree in Civil Engineering in the year 2012 from Rajasthan Technical University. He was Assistant Professor at Vyas College of Engineering and Technology, Rajasthan before joining Larsen and Toubro Technology Services as a Structural Engineer at Chennai in 2013. He has worked on structural designs of slabs-on-grade, pre-engineered buildings, machine foundations, steel connections among others. His research interests include dynamic analysis, pavement design and steel connections. 